\title{
Exploring the Pre-Novice Phenomenon in Undergraduate Nursing Education
}

\author{
Loretta J Aller* \\ Kent State University, USA \\ Submission: March 17, 2017; Published: May 25, 2017 \\ *Corresponding author: Loretta J Aller, Kent State University, USA, Email: laller@kent.edu
}

\section{Introduction}

\section{Background and significance}

There are 2,745,910 Registered Nurses (RN's) employed in the United States with an anticipated work force of 3.24 million RN's in practice by the year 2022 [1]. With the projected rate of 525,000 nurses leaving the profession, it is estimated that the total number of job openings for RN's will be 1.05 million by 2022 [1]. A total of 111,634 nursing students graduated from an accredited baccalaureate program in the United States between August 2013-July 2014 [2]. Of these students 63,857 had entrylevel baccalaureate status and 47,777 were RN's returning to obtain their bachelor of science in nursing (BSN) degrees [2].

Upon graduation and successful completion of the NCLEX licensure exam, these new graduates are deemed capable of providing safe nursing care to the population. Colleges of Nursing as well as the employers of these new RN's demand competent new graduates able to provide safe client care and they expect a smooth transition to practice. The new graduate rates of actual turnover or intent to leave the organization and/or profession within the first year of practice are staggering. In the United States, approximately 1 in 5 newly licensed RN's leave their first job within the first 12 months and 1 in 3 within the first 24 months [3]. The cost to replace one RN in the United States ranges from $\$ 10,098$ to $\$ 88,000$ (AACN, 2015) and Australia reports costs of $\$ 48,000-\$ 100,000$ [4]. Other countries report widely varying rates of new graduate turnover including Canada (60\%) [5], Australia (50\%) [6], South Korea (33.4\%) [7], and Sweden (20\%) [8].

In recognition of this crisis, AACN [2] has developed their 2017- 2019 Strategic Plan which includes objectives and initiatives to improve the quality and advancement of nursing education in the United States [2]. The National Council of State Boards of Nursing (NCSBN) has released the results of a longitudinal simulation study designed to provide data regarding the use of simulation as an alternative to traditional clinical experiences in nursing education [9]. New graduate RN orientation and mentorship guidelines are being reviewed with healthcare organizations instituting Nurse Residency programs intended to improve the outcomes associated with transition to practice [10]. Even with graduate nurse transition to practice programs, research indicates that outcomes remain dismal [11]

Vast resources are being directed at the problem of new graduate nurse turnover yet it remains a threat to the profession of nursing. Patricia Benner's Novice to Expert Theory (1984) has been cited throughout the literature as a framework for understanding the progressive development of nurses. Benner's theory defines as the entry point on the continuum of the development of a professional nurse to be the novice. However, the novice stage encompasses a wide range of individuals including nursing students, new graduate nurses and those nurses changing specialty work areas such as moving from a medical-surgical unit to a labor and delivery unit. This researcher proposes the need to explore the concept of nursing students as pre-novices; as a separate and distinct stage occurring before Benner's novice stage

\section{Domains of nursing knowledge: the practice domain}

Of the four theoretical domains of nursing as defined by Kim [12], the typology of practice is most relevant to the phenomenon of the pre-novice nursing student. Within the practice domain lie the concepts of clinical reasoning, prioritization, nursing decision making and nursing enactment [12]. Considering Benner's Novice to Expert theory (1984), all components of this domain develop beginning with the novice and progressing to the expert. As with the pre-novice, understanding the developmental process that occurs in each of these areas will be an important contribution to the theoretical foundation of nursing education.

A nursing students' ability to recognize a change in client condition and determine the reason for the change (clinical reasoning) is paramount to their academic success. Some students are able to recognize that something is wrong but then have no idea what to do about the problem. Others may continue 
to perform tasks in a check-box type fashion without seeing the larger picture of client deterioration. Recognizing the need for action and then deciding what to do (decision-making), and in what order (prioritization) are clear examples of the decisionmaking component of the practice domain.

The nursing enactment portion of the practice domain is also key in that some students given a client care scenario are able to sit down and write a comprehensive care plan. Being able to gather relevant data and deliver organized and effective client care to a real live human being may not be as easy. Student nurses, prior to graduation, are expected to be able to assimilate the knowledge they have learned in school and apply it to live client care situations. Given the previous descriptions regarding new nurse transition to practice issues, there is work to be done within the practice domain in nursing education.

\section{Purpose of the Review}

The purpose of this preliminary integrated review of the literature is to explore the state of the science surrounding the development of undergraduate nursing students as pre-novices. Included in this review are barriers faced by nurse educators and employers of graduate nurses, strategies being attempted to ease transition to practice and the outcomes associated with the existing system. Finally, the gap in the literature regarding the need for theoretical foundation will be presented.

\section{General Methods for Review Process}

\section{Search strategy and yield}

An integrated review of the state of the science was conducted via on-line searches as well as through interaction with regional, national and international organizations, councils and accrediting bodies involved in nursing education. Searches were conducted over the time period of 2014-2016. Web databases CINAHL, PubMed, Medline, ResearchGate, HealthSource (Academic Version), WorldCat, ProQuest, Education Resource Complete and EBSCO were searched with the following keywords used both independently and in various combinations: "experiential learning", "pre-novice", "Benner", "critical thinking", "situational awareness", "simulation", "new graduate nurses", "transition", "turnover", "novice" and "undergraduate nursing education". The searches retrieved a total of 798 articles.

\section{Inclusion/Exclusion Criteria}

Inclusion criteria used to screen the large volume of articles for relevance in this study were publication dates of 2010-2016 and while care was taken to ensure an international selection of articles, those chosen were limited to literature written in the English language. Lastly, articles were screened for the exclusion criteria to ensure than if there was a nursing program involved in the study, at least a portion of the sample must include students/ programs at the undergraduate bachelor of science in nursing (BSN) level. All full-text articles remaining were reviewed and duplicates removed leaving a total of 33 articles.
Finally, contact was made and resources explored within the Ohio Consortium of Nursing Learning Labs (OCONLL), the National Council for the State Boards of Nursing (NCSBN), the American Association of Colleges of Nursing [2], the National League for Nursing [13] and the International Nursing Association for Clinical Simulation and Learning (INASCL) and the U.S. Bureau of Labor Statistics to ensure this literature review is up to date and thorough.

\section{Data Extraction and Management}

From the 33 eligible articles and the materials obtained from regional, national and international organizations, councils and accrediting bodies involved in nursing education, data was extracted. Articles were initially read through once to ensure comprehension of the aims, methods and findings. During the second reading of the articles, key components such as aim(s), research question(s), design, method, sample, setting, data analysis, findings and significance to nursing were considered and extracted for inclusion in one of three Integrated Review of Literature (IROL) tables. The need for three separate IROL tables became evident during the reading and extracting of information from the literature and other sources. Recognition of concepts as well as similarities and differences across and between the literature crystallized.

\section{Results/Findings of Integrative Review Process}

\section{Sample characteristics}

of the articles selected for inclusion in this review, both settings and samples varied widely with studies conducted in the United States ranging from single site to one study that used 23 sites across multiple states. Single sites were the most frequently used in Australia, Canada, South Korea, Singapore and Finland with settings ranging from private catholic and public universities to large multi-site healthcare systems. Sample sizes ranged from 5 to $>250$ participants with five studies using 6-50, eight studies with 51-100, seven studies with 101-200 and thirteen studies with $>250$ participants. It is difficult to generalize findings from these studies due to wide diversity in geographical location, cultural and economic implications and such variance in sample size. The studies with larger sample sizes may have more generalizable results however a private university setting is extremely different than a multi-site healthcare system in a different country.

\section{Sample Designs and Methods}

\section{Quantitative methods}

Publications included 33 primary research studies: nineteen (19) used quantitative methods, seven (7) mixed-methods and seven (7) qualitative. Of the quantitative designs, there were (15) studies that used a pre-test/post-test design: (6) were onegroup, (5) were two-group (3) were three-group and (1) had $>4$ groups. The remaining quantitative studies used post-test only (1), repeated measures longitudinal (4), repeated measures 
descriptive co-rrelational (1) and single time period descriptive correlational (3). Reliability and validity were inconsistently reported across these studies. Considering the nature of the phenomenon of the pre-novice nursing student and the literature related to barriers in education through transition to practice problems, the longitudinal design would be a preferred method if the researcher were exploring development from student to practicing nurse. In the four longitudinal studies, participant attrition was a factor inherent in the problem of new nurses leaving their positions and in some cases, the profession.

\section{Qualitative methods}

Of the qualitative research articles reviewed, (4) used grounded theory, (2) used descriptive exploratory and (3) used retrospective analysis designs. The selected qualitative approaches were appropriate based on the research questions of these studies. In all of the qualitative studies, researchers were interested in new graduate perception of the reasons nurses leave their positions and/or the profession within 1-2 years. Researchers were exploring influencing factors such as environment, manager and administrative support and perceptions of preparedness with the intent to uncover new information making their choice to use qualitative methodologies appropriate. Trustworthiness, member-checking, security of data and other indicators of rigor in qualitative methods were addressed in various levels of detail in (7) of the (9) studies.

\section{Mixed methods}

Seven of the studies used a mixed methods approach with questionnaires or surveys for the quantitative portion. Two used an open-ended question on the questionnaire and (4) used focus groups however only one of the two that used open-ended questions presented the findings of this portion of the study. Two of the four that used focus groups adequately addressed data collection, research team preparation and member-checking; the other two did not provide enough detailed information to determine the studies were rigorous. One study self-reported the research as mixed methods however, no qualitative component could be identified.

\section{Frameworks Used}

The frameworks cited in the articles reviewed vary widely and will be presented in two sections: those related to simulation as an alternative to live client experiences in nursing education and those used in research on transition to practice. Both bodies of literature are based around the phenomena of preparing individuals to become successful RN's, able to function effectively to provide safe client care. Yet across the spectrum of this preparation, there is a lack of consistency in theoretical foundation while in twelve (12) of the studies, no frameworks were mentioned.

\section{Simulation as a Strategy in Nursing Education}

Several studies (6) cited Kolb's Experiential Learning Theory as the foundation. This theory explores learning outcomes which in the context of the articles reviewed were studied in simulated environments. Three (3) studies combined Kolb's Experiential Learning Theory with Benner's Novice to Expert Theory which allowed integration of both outcomes and the development of novices. The FIRST2 ACT model was used in one study to explore another aspect of safe client care which the authors presented as 'situational awareness'; observing whether or not participants were able to recognize and take action when a patients' condition deteriorated. The last framework cited once in this section of the literature was Perry's Schema of Cognitive and Ethical Development which added the ethical component not considered in the design of the other studies.

\section{New Graduate RN Transition to Practice}

The literature surrounding the content of new graduate RN's transition to practice cited numerous different theoretical foundations as the framework for the research. Theories cited included the Affective Critical Thinking Model, the Areas of Worklife Model, the Theory of Work-Life Balance, Appreciative Inquiry Theory, Bandura's Self-Efficacy Theory, Social Identity Theory, the Theory of Organisational Socialisation, Kanter's Theory of Structural Power in Organizations and the Psychological Capital Theory. As is evident, there is a complete lack of consistency in the theoretical foundations of the research related to the phenomenon of the pre-novice. Lack of a cohesive theory for this research may well be a contributing factor to the continued issues and negative consequences of unsuccessful transition to practice by new graduate nurses.

\section{Concepts and Variables}

All articles included in this review will be discussed in total in this section as there was evidence of researchers using some of the same concepts and variables both in nursing education literature as well as the studies that focused on new graduate transition to practice issues. The variables most frequently identified which were used inter-changeably were 'critical thinking' and 'decision-making' (CT-DM) (13 of the 33 articles reviewed). As with the lack of theoretical consistency mentioned in the previous section, the operational definitions of these variables were also varied. Seven (7) of the studies used 'knowledge' as a means of describing CT-DM with two (2) of these seven studies adding 'competence' and one of these two adding 'situational awareness' as a third component. 'Readiness to practice/NCLEX pass' was another concept used in two of the studies while 'cognitive development' was listed as a component of CT-DM in one article.

While the operational definitions of CT-DM were varied, the number of remaining dependent variables used in the studies is indicative of a lack of consensus regarding what concepts should be measured within the phenomenon of the pre-novice. The articles that studied pre-graduate nursing students (Appendix A) explored the dependent variables of 'satisfaction and confidence' (4), 'open-mindedness' (1), 'truth-seeking' (2), and 'judiciousness/maturity of judgment' (1). 
Among the articles exploring the issues of new graduate nurses transitioning to practice (Appendix B), 'job satisfaction' (5) was the most frequently studied dependent variable. 'Intent to leave', was also a variable studied but in variations such as 'intended/actual turnover from organization' (4), 'intended/ actual turnover from profession' (1), and occupational commitment (2). Remaining variables included presence or absence of 'support' (2), 'stressors' (1), 'empowerment' (1), 'environment and ethical climate' (1) and 'sense of belonging, accomplishment, worth and recognition' (1). 'Confidence in reasoning' and 'competence' were the only two variables studied in both the pre-graduate nursing students and new graduate nurses (4).

As with the diversity of theoretical frameworks, so too is the wide variance in those concepts researchers studied in an effort to enhance CT-DM in pre-graduates and improve new graduation adaptation to practice. This lack of agreement across the literature regarding consistent variables being studied undermines the development of a solid base of knowledge to aid the understanding of how to successfully educate and transition new nurses into practice. Finally, it should be noted that among all of the studies included in this review, there were (37) different tools used to collect the data with only one of the tools being used more than once: the California Critical Thinking Disposition Inventory which was used in two studies. Reliability and validity for the quantitative tools were presented adequately in $<30 \%$ of the literature and trustworthiness as an indicator of the rigor of the qualitative studies was acknowledged and well-described in $<20 \%$ of the studies in which this level of description is expected.

\section{Findings and Gaps}

\section{What is known}

Potential healthcare employers of new graduates expect competent, prepared nurses capable of providing safe nursing care. Nurse residency programs, changes in orientation and mentoring and the exploration of factors impacting outcomes are being studied. The issues with transition to practice of new graduate nurses has been well-established and extensively researched yet we still have unacceptably high rates of turnover, burnout and intent to leave a position or the profession [14-27].

Organizations with an interest in nursing education are committing vast resources with the intent of trying to improve the quality and marketability of new graduates. Colleges of nursing are facing barriers to providing those learning opportunities necessary to ensure new graduates have the critical thinking and decision-making capabilities to 'hit the ground running' in an environment that is faster paced and more technologically advanced than at any time in the past. Challenges such as competition for clinical sites, faculty shortages and restrictions on student access to electronic medical records have driven nursing programs to integrate simulation and virtual scenarios into their curriculum. While organizations and accrediting bodies have granted some leniency on the required clinical hours allowing educational institutions to use simulation as an alternative to traditional direct live patient interactions, the literature regarding the benefits of this teaching strategy remain highly contradictory [28-37].

\section{Where do we go from here?}

As is evident from this integrated review of the literature, the problem of new nurse transition to practice remains. While nurse residency programs and changes on the employer side and the integration of questionably beneficial simulation on the educator side are being implemented, we are missing the connection between the two arenas. The lack of consistent theoretical underpinnings reaching from the nursing student through to the practicing nurse may well be the missing link.

While Patricia Benner's (1984) Novice to Expert Theory is widely used in both the academic and practice realms as a foundation for understanding how a nurse develops; she defines the nurse at the novice level as including nursing students, new graduate nurses and those nurses changing specialty work areas [38-48] such as moving from a medical-surgical unit to a labor and delivery unit. Based on this definition, pre-graduate nursing students who have not yet completed their formal education to become a registered nurse (RN) nor taken and passed the licensure exam or independently practiced nursing in any setting are grouped together with those nurses who have completed these tasks.

This researcher proposes and has begun research preparations under the premise that there is a difference between the nursing student, specifically the pre-licensed, undergraduate junior/senior level bachelor of science in nursing (BSN) student, and other novices as described in the current theory; a phenomenon which occurs before the novice stage...the pre-novice. Questions such as "Is there a need for an extension of this theory to include the pre-novice? Are these pre-novices developmentally different and unique?" are not only valuable, they are crucial. If we discover that these pre-novices are developmentally different from those other novices, future research on how to improve or facilitate the developmental process of the pre-novice nursing student will allow curricular decisions to be made on a strong theoretical foundation. Preparing our new graduates to provide safe and effective, high quality care begins during their student journey - before they are faced with the challenges inherent in the transition to practice.

\section{References}

1. Bureau of Labor Statistics (2015) Occupational employment and wages report: 29-1141 Registered nurses, USA.

2. American Association of Colleges of Nursing (2015).

3. Robert Wood Johnson Foundation (2014) Nearly one in five new nurses leaves first job within a year, according to survey of newly licensed registered nurses.

4. Henderson A, Ossenberg C, Tyler S (2015) What matters to graduates: An evaluation of a structured clinical support program for newly graduated nurses. Nurse Educ Pract 15(1): 225-231. 
5. Boamah S, Laschinger H (2016) The influence of areas of worklife fit and work-life Interferenceon burnout and turnover intentions among new graduate nurses. J Nurs Manag (24): e164-e174.

6. Parker V, Giles M, Lantry G, McMillan M (2014) New graduate nurses' experiences in their first year of practice. Nurse Educ Today 34(7): 150-156.

7. Cho SH, Lee JY, Mark BA, Yun SC (2012) Turnover of new graduate nurses in their first job using survival analysis. J Nurs Scholarsh 44(1): 63-70.

8. Rudman A, Gustavsson P, Hultrell D (2014) A prospective study on nurses' intention to leave profession during their first five years of practice in Sweden. Int J Nurs Stud 51(4): 612-624.

9. Hayden JK, Smiley RA, Alexander M, Kardong-Edgren S, Jeffries P (2014) The NCSBN national simulation study: a longitudinal, randomized, controlled study replacing clinical hours with simulation in prelicensure nursing education. Journal of Nursing Regulation 5(2).

10. Chappell K, Richards K, Barnett S (2014) New grad nurse transition programs and clinical leadership skills in novice RNs. J Nurs Adm 44(12): 659-668.

11. Laschinger H, Grau A (2012) The influence of personal disposition factors and organizational resources on workplace violence, burnout, and health outcomes in new graduate nurses: A cross-sectional study. Int J Nurs Stud 49(3): 282-291.

12. Kim H (2010) The nature of theoretical thinking in nursing. New York, USA.

13. National League for Nursing (NLN) (2016) Nursing education simulation programs.

14. Ballard J, Mead C, Richardson D, Lotz, A (2012) Impact of diseasespecific orientationon newgraduate nurse satisfaction and knowledge retention. J Neurosci Nurs 44(3): 168-174.

15. Chachula K, Myrick F, Yonge $O$ (2015) Letting go: How newly graduated registered nurses in Western Canada decide to exit the nursing profession. Nurse Educ Today 35(7): 912-918.

16. Chandler GE (2012) Succeeding in the first year of practice: Heed the wisdom of novice nurses. J Nurses Staff Dev 28(3): 103-107.

17. Chappell K, Richards K, Barnett S (2014) New grad nurse transition programs and clinical leadership skills in novice RNs. J Nurs Adm 44(12): 659-668.

18. Chenevert D, Jourdain G, Vandenberghe C (2016) The role of highinvolvement work Practicesand professional self-image in nursing recruits' turnover: A three-year prospective study. Int J Nurs Stud 53(9): 73-84.

19. Cleary M, Horsfall J, Jackson D, Muthulakshmi P, Hunt G (2013) Recent graduate nurse views of nursing, work and leadership. J Clin Nurs 22(19-20): 2904-2911.

20. Flinkman M, Salantera S (2015) Early career experiences \& perceptions - a qualitative Explorationof the turnover of young registered nurses and intention to leave the nursing profession in Finland. J Nurs Manag 23(8): 1050-1057.

21. Klingbeil C, Schiffman R, Ziebert C, Totka J, Schmitt C, et al. (2016) Transitions of experienced and new grad nurses to a pediatric hospital. J Nurses Prof Dev 32(4): 198-204.

22. Kovner CT, Brewer CS, Fatehi F, Jun J (2014) What does nurse turnover rate mean and what is the rate? Policy Politics and Nursing Practice 15(3-4): 94-71.

23. Leong YM, Crossman J (2014) New nurse transition: success through aligning multiple identities. J Health Organ Manag 29(7): 1098-1114.
24. Numminen O, Leino-Kilpi H, Isoaho H, Meretoja R (2015) Newly graduated nurses'competence and individual and organizational factors: A multivariate analysis. J Nurs Scholarsh 47(5): 446-457.

25. Numminen O, Ruoppa E, Leino-Kilpi H, Isoaho H, Hupli M, et al. (2016) Practice environment and its association with professional competence and work-related factors: Perception of newly graduated nurses. J Nurs Manag 24(1): e1-e11.

26. Phillips C, Esterman A, Kenny A (2015) The theory of organizational socialisation and its potential for improving transition experiences for new grad nurses. Nurse Educ Today 35(1): 118-124.

27. Tuckett A, Winters-Chang P, Bogossian F, Wood M (2015) Why nurses are leaving the profession...lack of support from managers': What nurses from an e-cohort study said. Int J Nurs Pract 21(8): 359-366.

28. Adamson K (2012) Piloting a method for comparing two experiential teaching strategies. Clinical Simulation in Nursing 8(8): e375 - e382.

29. Buykx P, Kinsman L, Cooper S, McConnell-Henry T, Cant R, et al. (2011) FIRST ${ }^{2}$ ACT: Educating nurses to identify patient deterioration - a theory-based model for best practice simulation education. Nurse Education Today 31(7): 687-693.

30. Howard V, Englert N, Kameg K, Perozzi K (2011) Integration of simulation across the undergraduate curriculum: Student\& faculty perspectives. Clinical Simulation in Nursing 7(1): e1-e10.

31. Mawson K (2014) Use of media technology to enhance the learning of student nurses in regards to auditory hallucinations. Int J Ment Health Nurs 23(5): 135-144.

32. Montenery S, Walker M, Sorensen E, Thompson R, Kirklin D, et al. (2013) Millennial generation student nurse's perceptions of the impact of multiple technologies on learning. Nurs Educ Perspect 34(6): 405-409.

33.

34. McKenna L, Missen K, Cooper S, Bogossian F, Bucknall T, et al. (2014) Situation awareness in undergraduate nursing students managing simulated patient deterioration. Nurse Educ Today 34(6): e27-e31.

35. Shinnick M, Woo M (2013) The effect of human patient simulation on critical thinking and its predictors in pre-licensure nursing students. Nurse Educ Today 33(9): 1062 -1067.

36. Shinnick M, Woo M, Evangelista L (2012) Predictors of knowledge gains using simulation in the education of prelicensure nursing students. J Prof Nurs 28(1): 41-47.

37. Weatherspoon D, Phillips K, Wyatt T (2015) Effect of electronic interactive simulation on senior BSN students' critical thinking and clinical judgment skills. Clinical Simulation in Nursing 11(2): 126-133.

38. Benner P (1984) From novice to expert: Excellence and power in clinical nursing practice. Addison-Wesley Publishing, Menlo Park, California, USA.

39. Klaassen J, Smith K, Wit J (2011) The new nexus: Legal concept instruction to nursing students, teaching-learning frameworks, and high fidelity human simulation. Journal of Nursing Law 14(3-4): 85-90.

40. Laschinger HK, Cummings G, Leiter M, Wong C, MacPhee M, et al. (2016) Starting out: A time-lagged study of new graduate nurses' transition to practice. Int J Nurs Stud 57(1): 82-95.

41. Manee F, Nadar M, Jahrami H (2012) Learning styles of allied health sciences students at Kuwait University. International Journal of Therapy and Rehabilitation 20(5): 80-91.

42. McCormick K (2014) The effect of learning styles, critical thinking disposition, and critical thinking on clinical judgment in senior baccalaureate nursing students during human patient simulation. 
Doctoral dissertation -Southern University and Agricultural and Mechanical College, Baton Rouge, Louisiana, USA.

43. Ohio Consortium of Nursing Learning Labs (OCONLL) (2016) Innovative approaches using simulation in the classroom and simulation laboratories.

44. Poore J, Cullen D, Schaar G (2014) Simulation-based inter professional education guided by Kolb's experiential learning theory. Clinical Simulation in Nursin 10(5): e241-e247.

45. Secomb J, McKenna L, Smith C (2012) The effectiveness of simulation activities on the cognitive abilities of undergraduate third-year

This work is licensed under Creative

Commons Attribution 4.0 License nursing students: a randomized control trial. J Clin Nurs 21(23-24): 3475-3484.

46. Pineau Stam LM, Spence Laschinger HK, Regan S, Wong C (2015) The influence of personal and workplace resources on new graduate nurses' job satisfaction. J Nurs Manag 23(2): 190-199.

47. Valler-Jones T, Meechan R (2011) Simulated practice -a panacea for health education? British J Nurs 20(10): 628-631.

48. Wood RY, Toronto CE (2012) Measuring critical thinking dispositions of novice nursing students using human patient simulators. J Nurs Educ 51(6): 349-352.

\section{Your next submission with Juniper Publishers will reach you the below assets}

- Quality Editorial service

- Swift Peer Review

- Reprints availability

- E-prints Service

- Manuscript Podcast for convenient understanding

- Global attainment for your research

- Manuscript accessibility in different formats

( Pdf, E-pub, Full Text, Audio)

- Unceasing customer service

Track the below URL for one-step submission https://juniperpublishers.com/online-submission.php 